VII JORNADAS DE DIFUSIÓN DE LA INVESTIGACIÓN Y EXTENSIÓN - FCV-UNL

RESUMEN EXTENDIDO

\title{
CRECIMIENTO Y CARACTERÍSTICAS FERMENTATIVAS DE Kluyveromyces marxianus EN MATRICES DERIVADAS DE LACTOSUERO
}

\author{
Gomez, $\mathrm{GA}^{1}$, Nagel $\mathrm{OG}^{2}$, Althaus $\mathrm{RL}^{2}$, Ceruti $\mathrm{RJ}^{1}$
}

${ }^{1}$ Instituto de Tecnología de Alimentos, Facultad de Ingeniería Química, Universidad Nacional del Litoral, Santiago del Estero 2829 - (3000) Santa Fe, Santa Fe, Argentina.

${ }^{2}$ Facultad de Ciencias Veterinarias, Universidad Nacional del Litoral, R.P.L. Kreder 2805 - (3080). Esperanza, Santa Fe, Argentina.

* Correspondencia: Gómez G.A., E-mail: gagomez11@gmail.com

\section{GROWTH AND FERMENTATION CHARACTERISTICS OF Kluyveromyces marxianus ON WHEY AND WHEY-BASED MATRICES}

\section{SUMMARY}

Milk whey has a high content of organic matter; therefore, uncontrolled discharge can cause environmental problems. An altern ative for whey utilization is the production of fermented alcoholic beverages by means of the yeast Kluyveromyces marxianus, able to use lactose as a carbon source. Four different liquid growth media were prepared: whey powder (SP) and demineralized whey powder (SPD) $(65 \mathrm{~g} / \mathrm{L})$ dissolved in sterilized distilled water; SPCal, similar to SP in composition, but sterilized and centrifuged to remove proteins, and milk permeate (PER). All media were fermented by 24 hours at $30^{\circ} \mathrm{C}$. Samples were taken every 8 hours, for pH, biomass, ethanol and lactose determination. K. marxianus (LFIQK1 strain) growth was similar in SP, SPD and SP Cal (biomass between $2-3 \mathrm{~g} / \mathrm{L}$ ) and lower in PER. Moderate $\mathrm{pH}$ decline was observed, final values being between 4,7 and 5,4. Significant lactose consumption was observed in every growth media, with final values around $12 \mathrm{~g} / \mathrm{L}$ and good ethanol production, especially for SP, SPD, and PER mediums $(17,0 \pm 0,7$; $17,6 \pm 0,5 ; 16,3 \pm 0,2 \mathrm{~g} / \mathrm{L}$ respectively). These results are encouraging for the production of alcoholic beverages from the studied media using $K$. marxianus as the fermentation agent.

Palabras clave: Lactosuero, Kluyveromyces marxianus, fermentación de lactosa, producción de etanol.

Keywords: Whey, Kluyveromyces marxianus, lactose fermentation, ethanol production.

La industria láctea genera grandes cantidades de lactosuero, principalmente como subproducto de la elaboración de quesos. El lactosuero presenta un elevado contenido en materia orgánica, fundamentalmente lactosa y proteínas del lactosuero, por lo que su vertido incontrolado puede ocasionar problemas ambientales. Sin embargo, la recuperación de componentes del lactosuero a través de estrategias de separación y concentración permite valorizar este subproducto para uso en la industria alimentaria. El permeado de suero o leche es un subproducto de la aplicación de tecnologías de ultrafiltración por membranas para concentrar proteínas lácteas, que por su elevado contenido de lactosa retiene gran parte del potencial contaminante del lactosuero. Una alternativa interesante para la utilización de estas matrices es el empleo de la levadura facultativa $K$. marxianus, debido a su capacidad para utilizar lactosa como fuente de carbono (Fonseca et al., 2008). Entre las diversas aplicaciones investigadas anteriormente, se ha 
propuesto el uso de esta levadura para la producción de etanol como biocombustible (Sansonetti et al., 2009). Sin embargo, el carácter GRAS de la levadura (Fonseca et al., 2008) permite también evaluar su uso para la producción de bebidas alcohólicas fermentadas. En el presente trabajo, se propone explorar las características básicas de crecimiento y fermentación de la levadura $K$. marxianus en lactosuero y diferentes medios derivados, así como evaluar su potencialidad para la producción de bebidas alcohólicas fermentadas.

Se utilizó la levadura $K$. marxianus LFIQ K1, aislada a partir de Kefir (FIQ-UNL). Para la preparación de los medios de cultivo se emplearon lactosuero y lactosuero parcialmente desmineralizado en polvo (La Cristina, S.A.) y permeado de leche obtenido de leche entera por ultrafiltración (membrana Koch HFK-131). Para los repiques se utilizó medio lactosado (4\% lactosa, $1 \%$ peptona de carne y $0,5 \%$ extracto de levadura). Se prepararon 4 medios de cultivo diferentes, por agregado de agua destilada estéril a suero y suero desmineralizado en polvo en una proporción $65 \mathrm{~g} / \mathrm{L}$ (medios SP y SPD, respectivamente); medio SP Cal, preparado de igual manera a SP, pero esterilizado en autoclave $\left(121^{\circ} \mathrm{C}, 15\right.$ min) y centrifugado para remover proteínas; y medio PER (permeado de leche). La cepa fue reactivada en medio lactosado a partir de estría MEA $\left(30^{\circ} \mathrm{C}, 24 \mathrm{~h}\right)$ y un segundo repique $\left(30^{\circ} \mathrm{C}, 24 \mathrm{~h}\right)$ al $25 \%$ en medio lactosado. Para el inóculo, se centrifugaron $40 \mathrm{~mL}$ del segundo repique, se resuspendió en $5 \mathrm{~mL}$ de solución fisiológica estéril y se agregó a cada medio. Los cultivos se realizaron por duplicado en frascos de borosilicato de $500 \mathrm{~mL}$ tapados con trampa de agua para permitir la salida de gas, agregando $400 \mathrm{~mL}$ de medio a cada frasco. Las fermentaciones fueron a $30^{\circ} \mathrm{C}$ y $24 \mathrm{~h}$ sin agitación. Se tomaron muestras cada 8 horas y se midió $\mathrm{pH}$ ( $\mathrm{pH}$-metro Horiba Laqua twin). La biomasa fue estimada por peso seco (g peso seco/L medio de cultivo) secado en estufa $\left(80^{\circ} \mathrm{C}, 24 \mathrm{~h}\right)$. La concentración de lactosa se evaluó por hidrólisis con la enzima $\beta$-galactosidasa (Lactozym 3000 L HP G, Novozymes) y posterior cuantificación de glucosa por técnica enzimática colorimétrica (Wiener lab). La concentración de etanol se determinó por método enzimático UV (Roche Cobas). El análisis estadístico se efectuó por ANOVA y comparación múltiple de medias (test LSD) utilizando el software Statgraphics.

Se observó crecimiento similar de $K$. marxianus (Fig. 1A) para SP, SPD y SP Cal, con valores finales de biomasa entre 2 y $3 g / L$, y significativamente menor $(P<0,05)$ para PER. Se observaron (Fig. 1B) descensos moderados de $\mathrm{pH}$ (entre 1,3 y 1,8 ) en todos los medios, con valores finales $4,7 \pm 0,1 ; 5,0 \pm 0,1 ; 4,8 \pm 0,1$ y $5,4 \pm 0,0$ para SP, SPD y SP Cal y PER, respectivamente. La cepa de $K$. marxianus utilizada presentó buena fermentación de lactosa (Fig. 1C). En todos los casos, el mayor porcentaje fue consumido en las primeras $16 \mathrm{~h}$, particularmente entre las 8 y $16 \mathrm{~h}$ de experiencia. Si bien las concentraciones iniciales de lactosa entre los distintos medios eran diferentes $(P<0,05)$, no se observaron diferencias significativas $(P>0,05)$ entre las concentraciones finales
(11-13 g/L). El consumo máximo de lactosa se observó en SPD (75\% de remoción). El mayor porcentaje de alcohol ( $75 \%$ o más) se produjo entre las 8 y las $24 \mathrm{~h}$, con pico entre las 8 y las $16 \mathrm{~h}$ para SP y PER, y las últimas $8 \mathrm{~h}$ para SPD y SP Cal. Los valores finales de etanol fueron similares $(P>0,05)$ para los medios $S P, S P D$ y $P E R$, con concentraciones de $17,0 \pm 0,7 ; 17,6 \pm 0,5 ; 16,3 \pm 0,2 \mathrm{~g} / \mathrm{L}$, respectivamente, mientras que fueron menores $(P<0,05)$ para SP Cal. Se observó un rendimiento muy cercano al $100 \%$ del valor teórico máximo $(0,538 \mathrm{~g}$ de etanol/g de lactosa consumida) en SP y rendimientos menores en los restantes, posiblemente debido a la remoción parcial de proteínas (SP cal y PER) o sales (SPD). Además, el valor de rendimiento encontrado en SP es superior al informado previamente con lactosuero y otras cepas de K. marxianus (Sansonetti et al., 2009; Zopplellari y Bardi, 2013). En vistas a la obtención de una bebida alcohólica fermentada, los niveles de etanol final resultan satisfactorios en todos los casos. Los resultados obtenidos resultan alentadores en cuanto al uso de la levadura $K$. marxianus para la producción de bebidas alcohólicas fermentadas a partir de las matrices ensayadas, solas o en combinación con jugos de frutas fermentados.
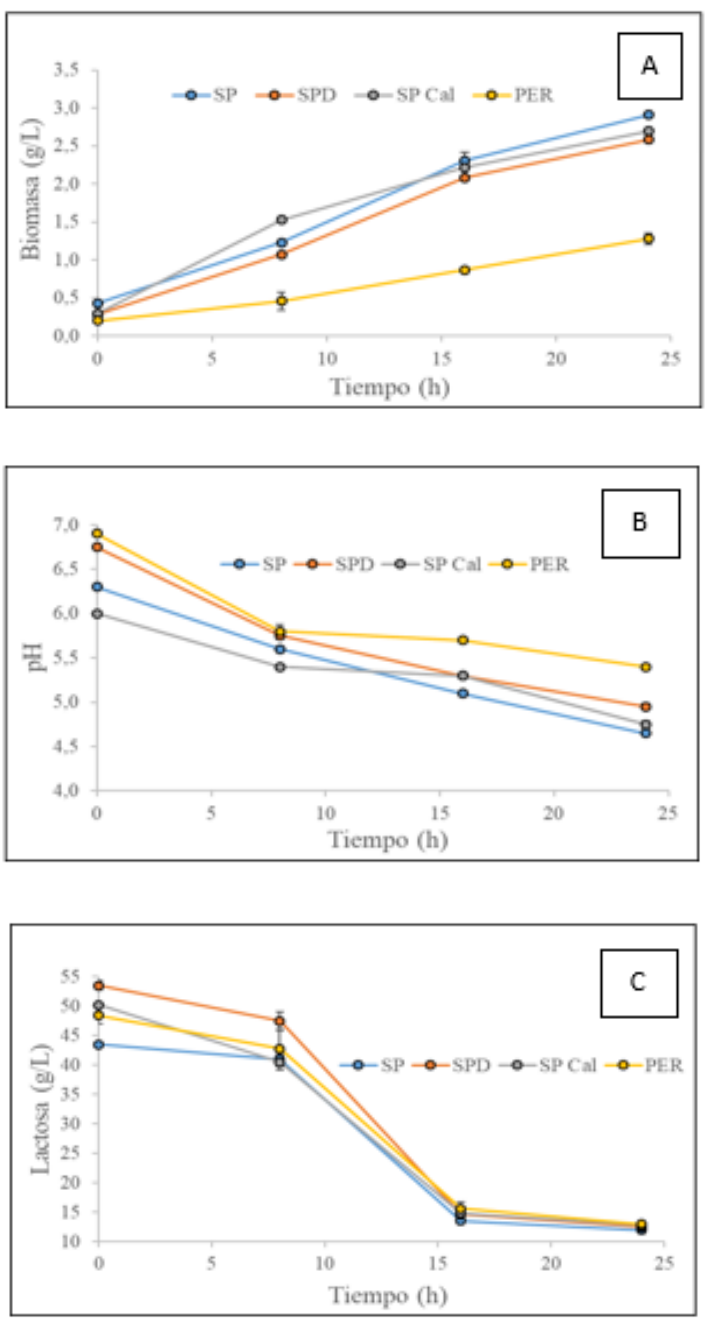


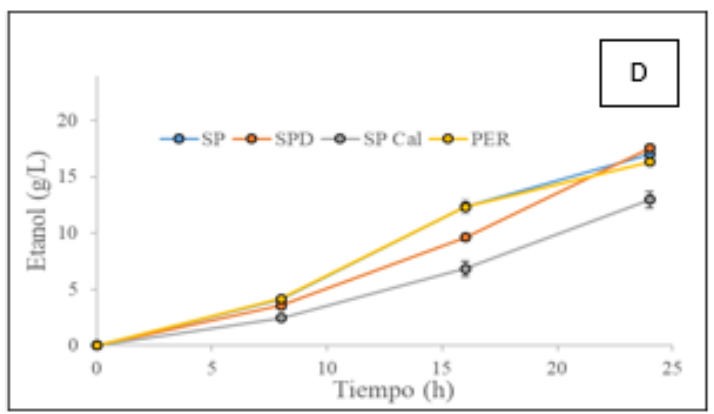

Figura 1: Biomasa (A), pH (B), concentración de lactosa (C) y etanol (D) en matrices de origen lácteo fermentadas con Kluyveromyces marxianus.

\section{Bibliografía}

Fonseca GG, Heinzle E, Wittmann C, Gombert, AK. 2008. The yeast Kluyveromyces marxianus and its biotechnological potential. App/ Microbiol Biot, 79(3): 339-354.

Sansonetti S, Curcio S, Calabrò V, lorio G. 2009. Bio-ethanol production by fermentation of ricotta cheese whey as an effective alternative non-vegetable source. Biomass Bioenerg, 33(12): 1687-1692.

Zoppellari F, Bardi L. 2013. Production of bioethanol from effluents of the dairy industry by Kluyveromyces marxianus. New Biotechnol, 30(6): 607-613. 